\title{
Art and Reality in The Arbor (2010)
}

\author{
Cecília Mello \\ University of São Paulo (Brasil) \\ E-mail: cicamello@yahoo.co.uk
}

\begin{abstract}
This article offers an in-depth analysis of 2010 British film The Arbor by Clio Barnard. The director's debut feature is a groundbreaking work dedicated to the lives of playwright Andrea Dunbar and her eldest daughter Lorraine. Dunbar grew up in the Buttershaw Estate in Bradford and drew on her own experiences to write her first play The Arbor at the age of 15, followed by Rita, Sue and Bob Too!. She struggled with alcoholism and died of a brain haemorrhage in 1990, at the age of 29. Lorraine's life followed down a difficult path as she became a drug addict and was jailed for manslaughter for causing the death of her two-year old child by gross neglect. My aim is to explore how the film combines different media, namely theatre, television and radio, in a cinematic experience defined by multiple registers and multiple voices, and how this structure works towards creating as much as conserving individual and collective memories, highlighting the fictional nature of memories. This leads to a reflection on the lip-synching technique, employed as the main vehicle for memory in the film, which provokes as much empathy and compassion as it does critical thinking, thus turning Brecht's binary equation reason-emotion in its head. ${ }^{1}$
\end{abstract}

Keywords: realism, intermediality, British cinema, Brecht, film editing.

Lorraine Dunbar stands on an empty stage and reads out the final words from the verbatim play A State Affair by Robin Soans (2000). Her presence on screen and on stage seems uncanny, almost phantasmagorical. It is her voice we hear, reading from the book of the play ten years after it was first staged by the "Out of Joint" theatre company at the Soho Theatre in London, under the direction of Max Stafford-Clark. Then, Lorraine's words, extracted from interviews conducted with her at the Buttershaw estate in Bradford, were declaimed by actor Emma Rydal. Now Lorraine speaks the words again, yet on screen we see actor Manjinder Virk lip-synching to their sound. What follows is one of the most powerful ellipses of contemporary British cinema, sending us back to the 1980s.

1 Research for this article was supported by FAPESP - São Paulo Research Foundation, Brazil. 
Sitting at the audience is none other than Lorraine's mum, Andrea Dunbar. She smokes a cigarette and listens to what her daughter has to say about her, a speech that ends with these words: "One night, when she thought I was asleep, I heard her say she wished she'd had an abortion with me. How could she say that? Every day I feel hurt, pain, anger, hate. That's why I went on heroin...to block out those feelings". [Figs. 1-2.]

This scene belongs to the film The Arbor, made in 2010 by artist filmmaker Clio Barnard. The director's debut feature, co-produced by art organization Artangel, is a groundbreaking work dedicated to the lives of playwright Andrea Dunbar and her eldest daughter Lorraine. Andrea grew up in the Buttershaw estate in Bradford, England, and drew on her own experiences to write her first play The Arbor in 1977, at the age of 15. The play was later developed and performed at the Royal Court Theatre "Young Writer's Festival" in 1980, under director Max Stafford-Clark, who was so impressed by Andrea's precocious talent that he commissioned a second play, Rita, Sue and Bob Too (1982), also set at the Buttershaw estate and equally based on the author's own experiences. Through the 1980s, Andrea's work was critically acclaimed and she received a great deal of media attention, but at the same time she struggled with alcoholism and died from a brain haemorrhage in 1990, at the age of 29. Ten years after Andrea's untimely death, director Max Stafford-Clark and writer Robin Soans revisited the Buttershaw estate and collected interviews with several of its residents, later placed in a dramatic context and edited as the verbatim play A State Affair, written from the actual words and phrases recorded on site. In a community weakened by heavy drugs and crime, Stafford-Clark and Soans came across Lorraine, the fruit of Andrea's inter-racial relationship with Yousaf, originally from Pakistan. Lorraine's life had followed down a difficult path after her mum's death, as she became addicted to heroin and crack cocaine.

The Arbor thus appears as third in a lineage of works concerned with life at the Buttershaw estate, and was also inspired by a wish to return to this place and not only reflect on its current condition but also on its previous representations in theatre and on film. For two years, director Clio Barnard recorded lengthy interviews with members of Dunbar's family, neighbours and friends, most still residents of the estate. It was during this time that Barnard found out how Lorraine's life had taken a turn for the worse since the production of A State Affair: in 2007 she had been jailed for manslaughter by gross neglect for the tragic death of her two-year old son Harris, who overdosed on his mum's methadone. Lorraine then became a focal point of Barnard's interviews, and in more than one 
occasion the director uses Andrea's plays, personal letters and footage from old television programmes as a means to trigger Lorraine's childhood memories. The interviews were then edited in the manner of an audio screenplay, which became the main guiding line for the film, composed from a variety of sources such as television programmes, an outdoors performance of Andrea's eponymous play and, most notably, the technique by which actors lip-synch to the pre-recorded interviews collected by Barnard, in order to reconstruct the two tragic lives.

In this article, I will endeavour to show how The Arbor's aesthetic experience with mixed media and the lip-synching technique puts into question accepted notions of fiction and documentary in film, connecting realism and intermediality in an original way. I will first reflect on how its complex editing structure manages to interweave different media, namely theatre, television and radio, to generate a cinematic experience defined by multiple registers and multiple voices. I will then look at how this original structure works towards creating as much as conserving individual and collective memories, highlighting a question analogous to the paradoxical nature of this film, that is, the fictional nature of real memories. This leads towards a reflection on the interview and the lip-synching techniques, employed as the main vehicle for memory in the film, which provokes as much emotion as it does critical thinking, thus turning Brecht's binary equation reasonemotion in its head. I will conclude by suggesting that The Arbor cannot be contained or explained by dualisms such as fiction-documentary, reason-emotion, form-content, history-poetry. It is a film that dares to speak of the real and of realism through an overtly reflexive and mediated structure, both continuing and departing from a certain tradition of British audiovisual media.

\section{Intermedial Film Editing and the Paradox of Memory}

The Arbor is, first and foremost, a film dedicated to the lives of Andrea and Lorraine Dunbar, and marginally to those around them such as Andrea's other children Lisa and Andrew, her siblings, ex-partners, friends and acquaintances, as well as Lorraine's foster parents Ann Hamilton and Steve Saul, all of whom lived or gravitated around the Buttershaw area in Bradford. Born and raised on Brafferton Arbor, at one point considered to be the toughest street of Buttershaw, Andrea drew inspiration to write her plays from her life experiences. In an interview to BBC Arena in 1980 she clearly stated her claim to realism: "You write about what's said. You don't lie. ... I called the play The Arbor because the street I lived on is called Brafferton Arbor. It's always known as The Arbor and a lot of 
these things actually happened on the street". ${ }^{2}$ It is no surprise, therefore, that her three plays The Arbor, Rita, Sue and Bob Too and Shirley (1986) contain almost a catalogue of social problems such as domestic abuse, alcoholism, racial tensions, teenage pregnancy and unemployment. Andrea writes from an "insider's" point of view and offers a picture of some of the effects of the severe social and economic changes that unfolded during the years of Thatcher's administration (1979-90), which saw the steady erosion of manufacturing jobs, the massive widening of the north/south divide and the gradual de-industrialization of the country. And despite the deep-rooted regional element in her work, it 'travelled south' to London's prestigious Royal Court Theatre and later gained national notoriety through its translation to cinema in the hands of director Alan Clark, via producer Oscar Lewenstein (Rita, Sue and Bob Too, 1987, co-produced by Channel 4 Films).

Art and reality are thus, from the outset, inextricable from each other in Andrea's work, and Barnard's film sets out to both investigate and question the nature of this relationship. In order to do so, it employs an overtly intertextual and intermedial structure in which the main reference is the theatre. While it is an accepted fact that film is, by its own essence, an intermedial phenomenon, the total work of art par excellence, The Arbor distinguishes itself by embracing intermediality into its style, narrative structure and character construction to the point of disturbing the audience's expectations with regards to the notion of documentary film and its modes of representation. It is also a well-known fact that any documentary contains a fictional element, an issue that has been widely discussed in audiovisual theory. ${ }^{3}$ Yet The Arbor seems to pose a more complicated problem. It concerns itself with true stories and has an ethical responsibility to the lives of the people behind these stories, which, as Bill Nichols points out in relation to documentaries in general, "though represented in the film, extend well beyond it" $(1991,109)$. At the same time, other elements such as the play's performance, the lip-synching technique and the fact that The Arbor was shot with a RED ONE Digital camera, as analogous to $35 \mathrm{~mm}$ as light and portable DV cameras would be to the immediacy of $16 \mathrm{~mm}$ and $8 \mathrm{~mm}$, swerve the film away from documentary conventions. Its style has little to do with the urgency of "direct cinema" or "cinéma vérité," experiences associated with the $16 \mathrm{~mm}$ format and which seem to have returned to the fore with the rise of digital technology and the possibilities it affords. Moving against the tide, The Arbor was storyboarded

2 From BBC Arena, 1980, extract included in Clio Barnard's film The Arbor.

3 See, for instance, Nichols (1991, 107-198). 
and shot in the manner of fiction, "with actors hitting their marks and carefully lit tracking shots" (Barnard quoted in Edwards 2010). Moreover, regardless of the various sources and registers used in the film, the editing employed is far removed from a rapid or fragmented style; rather, it gently interweaves the different intermedial strands as if composing a mosaic. Hence the impossibility of solving this film's paradox by either saying that it introduces fictional elements into a documentary or that it brings the "document" (such as interviews, letters and television/film footage) into fiction. The vague impression one has when confronted with its heterogeneous structure is that The Arbor cannot be defined in or against these terms. Documentary is no longer the opposite of fiction, and fiction no longer the opposite of documentary, just as cinema is neither the same nor the opposite of other media.

In order to assess how the film combines different media and different sensory regimes through the editing, it is important to consider its intermedial and intertextual structure in some detail. The Arbor is composed of five distinct but interrelated strands. Its backbone is made of the audio interviews conducted by Barnard, which present a contradictory view of the lives of Andrea and Lorraine. This audio material was edited in the form of an audio-play, akin to a radio documentary, and then lip-synched by actors playing the parts of the real people interviewed. The second strand in The Arbor are dramatic reconstructions of events mentioned during the interviews, a technique largely employed by television documentaries but that assumes different forms in the film. The third strand is a performance of Andrea's first play The Arbor, set in Brafferton Arbor itself, thus signalling the film's crucial relationship with theatre. The fourth strand refers to the medium of television and cinema itself, and is made up of footage from different programmes - documentaries or news broadcasts - relating to Andrea and Lorraine, such as a BBC Arena documentary from 1980, BBC News Look North from 1982, Yorkshire's TV The Great North Show from 1989 and BBC News Look North from 2007, as well as extracts from Clark's film Rita, Sue and Bob Too. Finally, the fifth strand corresponds to contemporary images of the estate, punctuating different sequences as well as opening and closing the film.

Despite the schematic description provided above, these five strands are intertwined in a very careful fashion through the film's editing. This shows not only how different media comingle rather than clash within the film's structure but also how fiction and documentary/art and reality are inextricable from each other in Andrea and Lorraine's world. One such example refers to the use of documentary footage from television and film archives. Rather than 
making "unmotivated appearances", these extracts are mostly introduced by the "characters" having access to them via television sets. The first instance of this can be observed in the scene where Lorraine opens an envelope inside her prison cell, containing some of her mum's personal letters, books and a DVD, which she then sits down to watch. We see an over-the-shoulder shot of her watching the television screen displaying images of Andrea in the BBC Arena documentary, followed by the television footage that, with a noticeable increase in the sound quality, takes over the whole screen. Here, and in other similar passages where Lorraine comments on her family on the television screen in a typical surprised or exclamatory tone ("Is that Pamela? Oh that's granddad!"), it is not only the intermedial nature of film that is highlighted but also the intermedial nature of Lorraine's memories, triggered by television programmes, books and letters belonging to another time. [Figs. 3-4.]

More prominently, the performance of Andrea's original play The Arbor in the green space by the estate is organically articulated with the other strands of the film, composing meaningful editing transitions. The scene in which "the girl" (the character based on Andrea is referred to as "the girl" in the play) gets hassled by a group of lads for sleeping with an Asian man, for instance, is followed by an interview with Andrea's friend Gemma Norman, who recalls how difficult it must have been for Andrea to have a mixed-race baby on the estate. Another such connection stresses an almost genetic or deterministic history of violence and abuse: it starts with Lorraine recalling how she was imprisoned and abused for over ten days by a drug dealer, followed by her reading from the book of the play inside her cell ("Act 2 Scene 8"), the sound bleeding over to the next shot where "the girl" lip-synchs to Lorraine's real voice, and finally the actual scene from the play, in which "the girl" tells a friend that Yousaf has beaten her up on a number of occasions, and how she worries about what will happen to the baby (Lorraine) once it is born. And even when the parallel is not established in such a straightforward way, it is still harrowing to see how life and art are integrated in The Arbor by hearing Lorraine say "I didn't ask to be conceived, I didn't ask to be born," and a few minutes later see Act 2 Scene 5 of the play in which "the girl" discusses with Yousaf whether she should or should not keep their baby.

The complex editing structure of the film [Figs. 5-8], which travels backwards and forwards in time and through different media, is also behind the scene described at the start of this article, which establishes a connection between the theatre - via A State Affair and the stage where Lorraine stands, and television documentary - via an extract from BBC Arena of Andrea sitting in the dark of 
the audience. The approximation of theatre and television through the medium of cinema thus makes it possible for Lorraine to "speak" to her mother 20 years after her death, and for Andrea to stare attentively and "listen" to her daughter. And it is not by chance that this interaction happens within the confines of a theatre, which works as a sort of intermediary between art and reality for both Andrea and Lorraine, who finally communicate through drama and through the shot-reverse shot editing structure.

The Arbor's use of mixed media and its complex editing structure also highlight the complex nature of memories, be them real or imagined, individual or collective. This happens especially through the drama reconstructions, as can be observed in one of the first sequences of the film where Lisa and Lorraine recall the day their bedroom caught fire. The reconstruction of this event is presented in a complex way, for Lorraine's memory of it does not match Lisa's: locked in a room as kids, Lorraine claims she lit a fire inside the bedroom to keep her siblings warm. Still according to Lorraine, they were trapped in their bedroom because Andrea had the habit of removing the door handle in order to keep them in. Yet Lisa claims it was her who had accidently pulled the handle out. The pairing of two accounts of one single event allows for the element of contradiction to emerge, a contradiction in this case inherent to Andrea's own personality: was she a terrible mum or a good mum? How is it that one child's memory of her can be so distinct from another child's memory? The uncertain circumstances of the event are ever so more enhanced by the uncanny impression of the lip-synching technique and by the fact that Lorraine and Lisa become, from the outset, multiple presences in the film: the two sisters are seen concomitantly as children, with child-actors playing their parts, and as adults, with adult actors playing their grown-up versions, lipsynching to the audio interviews or acting out the event. This doubling becomes a tripling if we add their real voices as a third presence.

These reconstructions also serve to emphasize both the present nature of memories and their spatial connection. In The Analysis of Mind, Bertrand Russell describes how the memory of a past event is in fact contained, or has a causal connection, with the present: "Everything constituting a memory-belief is happening now, not in that past time to which the belief is said to refer" (1924, 160). In The Arbor, the present tense of memories is explicit in re-occurring shots which bring together the past and the present through instances of internal editing. In the sequence described above, for instance, Andrea is seen writing in bed late at night in a reconstruction scene, and she is observed by grown-up Lisa and grown-up Lorraine, who wonder through the house - a site of memories 
- and recall the day the bedroom caught fire. Another poignant example can be found at the end of the sequence in which Andrea's brother David watches his younger self get arrested in the play's performance by Brafferton Arbor. As he is taken away by the police, the camera catches up with his older self, and through the lip-synching technique and the direct address he comments on his memory of the real event - which in turn had been transposed by Andrea onto her play. In this single shot David is also a triple presence - his young version in the play, his older version of the interview and his real voice, and this "multiplication of the self" works as a distancing effect in the film, at the same time conferring density and a prismatic quality to each "player" in the story.

As well as comingling in the edit in a way which allows for the encounter of past and present and for the communication of ideas, The Arbor's incorporation of mixed media also brings to the fore the complicated rapport between the very concept of memory and notions of truth and subjectivity. Lorraine's opening statement actually works as a point of entry into the theme of memory and its unstable nature, which renders it unreliable as a key to real events and the notion of truth: "I've got loads of childhood memories, but none of them are really good. I don't think you remember the good stuff". The subjective nature of memory, which usually appears as the reversal of Lorraine's declaration (as popular belief has it, one tends to remember the "good stuff"), suggests that the theme of memory in The Arbor is from the outset a complex one. Yet it also suggests that it is not interested in finding out "the truth" about what happened, or in siding with one perspective against another, in order to put forward a thesis. At the beginning of the film, for instance, Lorraine mentions something about having suffered sexual abuse as a child, but this allusion is never brought up again. Whether this actually happened or not, or who molested her, remains a mystery. Therefore, The Arbor quite clearly chooses to incorporate diffuse or disparate memories of real events, articulated through its intermedial structure so as to compose a fragmented portrait of these lives.

\section{Reason and Emotion}

The main vehicle for memory in The Arbor are the audio interviews conducted by the director with the following individuals: Lorraine Dunbar, Lisa Thompson and Andrew Dunbar, Andrea's children by different partners; Andrea's sisters Pamela and Kathy and brother David; Andrea's on and off partner Jimmy 'The Wig'; Lorraine's foster parents Steve Saul and Ann Hamilton; members of the 
Buttershaw community Gemma Norman and Jamie Timlin; theatre director Max Stafford-Clark and Out of Joint actor Gary Whitaker. As mentioned before, these interviews function as the film's backbone, which is to say that a great deal of emphasis is placed on the "word," most often than not the point of origin for the heterogeneous images arising from these people's recollections. The value of the "word" in the film is, primarily, that of a document: its soundtrack is mainly composed of real voices, real accents, intonations, pauses and stresses, and ultimately of the emotions which lie behind these voices. These words and emotions derive from the interview process, from an encounter with the filmmaker, a technique which is common currency in most types of documentaries. Here, Ismail Xavier makes an important point about the use of the interview by Brazilian documentarist Eduardo Coutinho: "The interview, as a public speech, reveals one's intimacy and transforms the person who speaks into a 'character' in the etymological sense of the word: a 'public figure'. ... Despite being a stranger, [the filmmaker] is an anticipated visitor, but there is an observance of decorum on both parts, marking a difference between a filmmaker's and a psychoanalyst's mode of listening'." (2009, 215.)

Xavier's reference to the interview as a public speech in relation to documentary practice is intrinsically related to what he terms the "camera-effect" $(2009,213)$. Despite using the interview as a structural element, The Arbor substitutes the camera-effect for the lip-synching technique, and this marks a crucial distinction between its mode of representation and most interview-based documentaries. Interviewees in the film were not subjected to the camera-effect, and so did not have to sustain the "camera gaze." The interview process was mediated by the less intrusive medium of the sound recorder and the microphone, and this is reflected in a difference in tone between the interviews collected for The Arbor and interviews on camera, allowing the speech to veer, more often than not, towards the confessional. While it would be wrong to equate the role of the interviewer with that of a psychoanalyst, the mode of listening employed and the nature of what is being said (Lisa, Lorraine and Andrew talk mainly about their mother) could suggest a parallel with a psychoanalytic mode of listening. This observation does not take into account the exact circumstances surrounding each interview, but only how these interviews are presented in the film, that is, in the form of free-flowing monologues rather than dialogues. Specially in Lorraine and Lisa's case, they often seem to be reclining on an analyst couch, with their backs to the listener, able to speak freely, given time to make sense of tragedy and painful memories, some recent and some buried deep under. Lorraine even 
seems to achieve some sort of progression in the process, as Barnard recalls: "There was a significant shift in my final interview with Lorraine. She began to accept that Andrea did love her, was able to stop blaming her and she was able to find it in herself to empathise with her mother" $(2010,3)$. Equally significant are the gaps in the two sisters' discourse - perhaps their unconscious at work - and which are partially filled in by mediation and remediation, that is, the play, the TV programmes and cinema itself, pointing once again to the conundrum that lies at the heart of memory and at the heart of the film.

Yet, as relevant as the parallel with psychoanalytic listening may be, it would still be naive to discuss these interviews as pertaining to the world of psychoanalysis. In spite of the less intrusive medium of sound recording, the interviews were still mediated, and those who spoke were not completely unaware of an "audience." Theirs is thus a "public speech," shaped and directed towards this audience, and later edited as an audio-play. Rather than choosing not to call attention to the artifice inherent to this process of recording and editing, the director embraced it in the boldest of ways by employing the lip-synching device. Real words by real people acquire different faces, bodies and movements, and with them a different value. ${ }^{4}$ This can be described, on a first level, as a Brechtian distancing device, which exposes the artifices of representation and invites an active mode of spectatorship. As is well known, Brecht's alienation effects for the theatre included a number of devices relating to structure, language, the non-illusionistic use of production elements and more prominently a particular approach to acting which proposed that the actor should stand apart from the character. In The Arbor, this is mainly achieved by the splitting of the common documentary interview technique in two, so that the voice and the face/body emerge from different sources to become a congregate actor. This meant that the actors were necessarily standing apart from their characters, engaged in an original delivery in which they were the ones who sustained the camera gaze rather than the real people speaking. And they did so in such a way that would have been impossible for Lorraine or Lisa or Steve or Anne or any of the other interviewees to do so, especially given the almost unbearably tragic nature of their memories.

The effect of this candid direct address to camera is of an at once theatrical anti-naturalist nature akin to Brecht's Epic theatre techniques and, paradoxically, of a heightened level of intimacy, which seems to draw the spectator in closer to the stories being recalled. As Barnard herself acknowledges: "I hoped to achieve a fine balance - so that, perhaps paradoxically, the distancing techniques might

$4 \quad$ With the exception of Gary Whitaker and Jamie Timlin, who appear as themselves. 
create closeness, allowing a push pull, so an audience might be aware of the shaping of the story but simultaneously able to engage emotionally" $(2010,2)$. Lorraine's and Lisa's testimonies are the finest examples of this: while there are shots in which they walk or perform tasks in their home or inside the prison, other moments employ the neutrality of the static medium close-up taken from a frontal angle. Unfettered by hand movements or distracting elements around them, they simply talk, sustaining the gaze of the camera or occasionally lowering their eyes, only to raise them again and face the lens, the director and the audience. It is so, perhaps, that the true innovative aspect of the lip-synching technique in The Arbor does not lie in its Brechtian distancing effect but in its reversal of Brecht's reason-emotion/mind-body dichotomies. As Lúcia Nagib points out à propos Brecht's notion of Verfremdungseffekt and his epic theatre, "revolutionary though this proposal was, it did not break away from well-established Western traditions. On the philosophical front, it embraces a Christian-inflected bodymind dualism harking back to Kantian metaphysics" $(2011,200)$. So, if on a first level the interviews in The Arbor appear to embrace distanciation, they in fact go one step further by combining it with emotion, for while their constructed nature is exposed, putting the spectator into a critical thus distanced position in relation to what is being told, they never seem to lose their emotional power, enhanced by the use of a less intrusive medium (the sound recorder) and by the inescapable direct gaze at the camera, sustained by the actors. [Figs. 9-10.]

This point of view, however, does not take into account the evolution perceived in Brecht's thoughts and theories during the 1930s and 1940s. As Bela Kiralyfalvi demonstrates (1990), while Brecht started off by rejecting any emotion-based aesthetic, which he perhaps superficially equated to Aristotle's notion of catharsis, he came to modify his allegiance to a reason-emotion, mind-body dualism by stating in letters and diary entries, and finally in his "Short Organum for the Theatre," that Epic Theatre does not deny or renounce emotion altogether, only "empathy," which would be inductive to passivity (Kiralyfalvi 1990, 28-29). So emotion came into the equation especially in his later plays, only a type of emotion

$5 \quad$ The Arbor's articulation of memory and its use of distancing techniques find a prolific parallel in Jia Zhangke's 24 City, shot in the Chinese city of Chendu in 2008. Jia's film is concerned with a specific place, Government Factory 420, which is being knocked-down to give room to a large complex of modern apartments and offices. Structured around interviews, the film combines the testimony of real characters with four 'fictional ones,' played by well-known actors Lü Liping, Joan Chen, Chen Jianbin and Zhao Tao. Interestingly, another film, made in the same year and that employs a similar technique, was Eduardo Coutinho's Jogo de Cena. Both similarly perform a reversal of Brecht's reason-emotion dichotomy, for while the audience is at all times aware of the artifices of representation, they still empathize and are moved by what is being said. 
not tied to a character's psychology but related to more generalized concepts such as the sense of justice and the importance of freedom. Brecht, however, continued to equivocally equate empathy with catharsis and thus continued to reject what he thought of as the Aristotelian dramatic theatre. Still, there is no denying that his late rejection of the reason/emotion duality signified a move in a different direction. To go back to The Arbor's sophisticated use of the alienation effect, it seems though that the question remains open. Could it be read as an instance of late Brecht's thoughts on Epic Theatre, given that it produces emotion despite distanciation? But what about empathy, which alongside sympathy could constitute a kind of identification, how does it fit into this equation? Perhaps The Arbor is a film which provokes empathy through distanciation, and if this is the case, it indeed poses a conundrum to the Brechtian-inflected aesthetics which refuse identification as politically backward.

Here, as way of conclusion, I would like to go beyond the issue of distanciation to suggest that The Arbor ultimately derives its political force from its aesthetic combination of realism and intermediality. The choice of approaching the relationship between art and reality via Andrea Dunbar's work and through the medium of cinema highlights a connection between The Arbor and the muchdiscussed tradition of social realism in the British cultural and artistic landscape. Barnard's film thus engages in a dialogue with this tradition and with the dialectics of realism at the heart of British cinema history, but rather than espousing a rhetoric of rupture or an opposite desire to establish some sort of continuity in relation to the thorny concept of social realism, it dares to do so in its own terms. This means that, in order to focus on the wider environment for both Andrea and Lorraine's tragedies, one set in the 1980s and the other in the 2000s, The Arbor embraces not representation but intermediality as the only aesthetic effect capable of revealing just how close real life and art can be. This to me seems to be the film's more overtly Brechtian gesture. In its highly sophisticated structure, all the different pieces that make up The Arbor - the street and the estate, its racism, violence and desolation, the people who lived or still live in it, the plays produced in and around it, and all the different voices, impressions, documents, actors and real people, everything comingles into a collective, intermedial memory of a community, as well as in the film itself. In the street, in the play and in the film called The Arbor, reality creates art and art creates reality. 


\section{References}

Aston, Elaine and Janelle Reinelt. 2001. Building Bridges: Life on Dunbar's Arbor, Past and Present. Theatre Research International vol. 26. no. 3: 285-293.

Barnard, Clio. 2010. Director's Statement. In The Arbor DVD booklet, Verve Pictures Limited, 1-3.

Casey, Edward. 2000. Remembering: A Phenomenological Study. Bloomington: Indiana University Press.

Edwards, Michael. 2010. Interview: Clio Barnard, Director of The Arbor. http:// whatculture.com/film/interview-clio-barnard-director-of-the-arbor.php Last accessed 26. 03. 2016.

Kiralyfalvi, Béla. 1990. The Aesthetic Effect: A Search for Common Grounds Between Brecht and Lukacs. Journal of Dramatic Theory and Criticism vol. 4. no. 2, Spring: 19-30.

Nagib, Lúcia. 2011. World Cinema and the Ethics of Realism. London \& New York: Continuum.

Nichols, Bill. 1991. Representing Reality: Issues and Concepts in Documentary. Bloomington and Indianapolis: Indiana University Press.

Russell, Bertrand. 1924. The Analysis of Mind. London: George Allen \& Unwin Ltd.

Xavier, Ismail. 2009. Character Construction in Brazilian Documentary Films: Modern Cinema, Classical Narrative and Micro-Realism. In Realism and the Audiovisual Media, eds. Lúcia Nagib and Cecília Mello, 210-223. Basingstoke: Palgrave Macmillan.

\section{List of Figures}

Figures 1-2. A powerful ellipsis: Lorraine speaks to her mother Andrea.
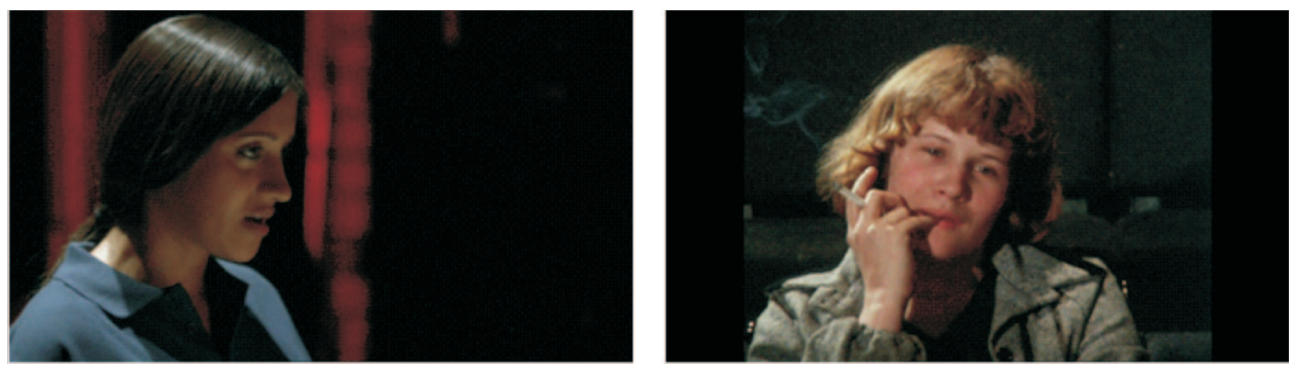
Figures 3-4. Lorraine's intermedial memories.
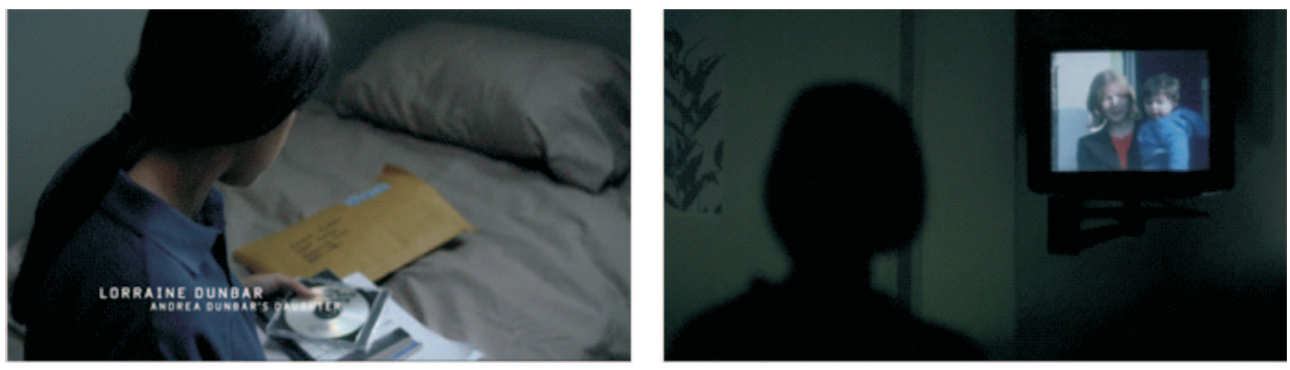

Figures 5-8. Intermedial Editing.
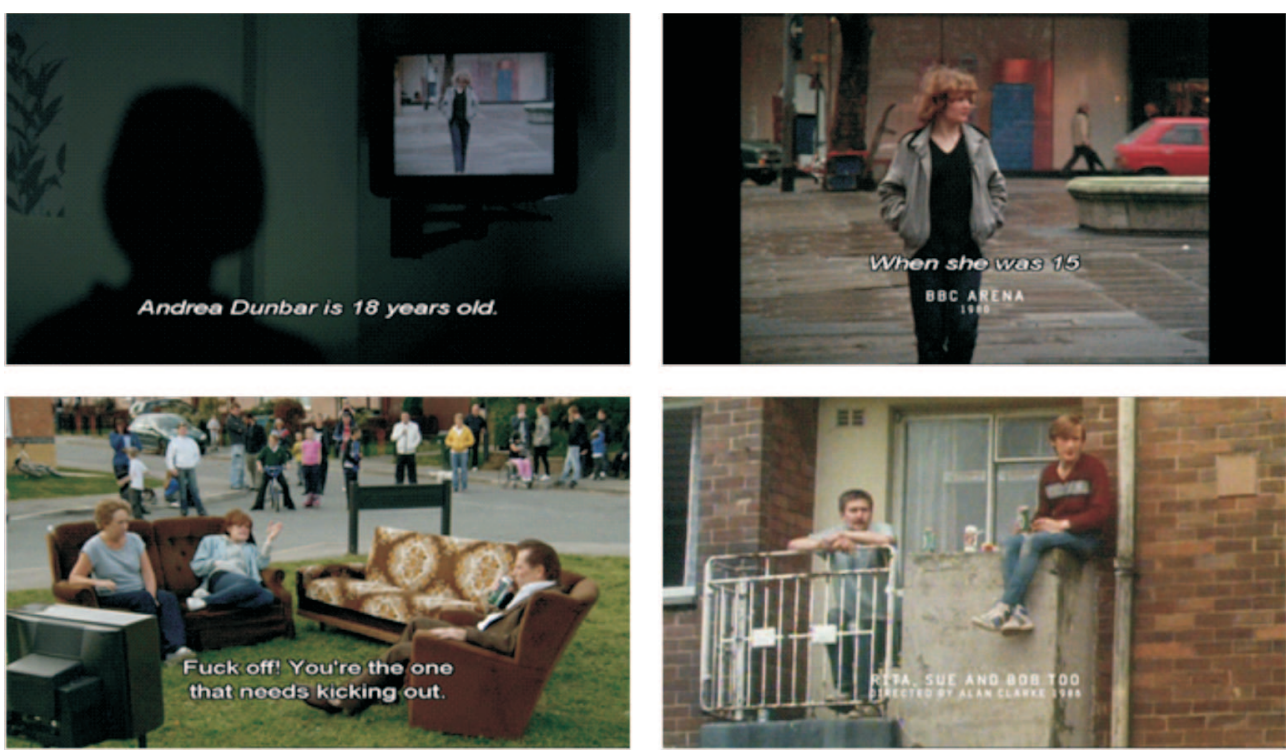

Figures 9-10. Lisa and Lorraine sustain the camera gaze.
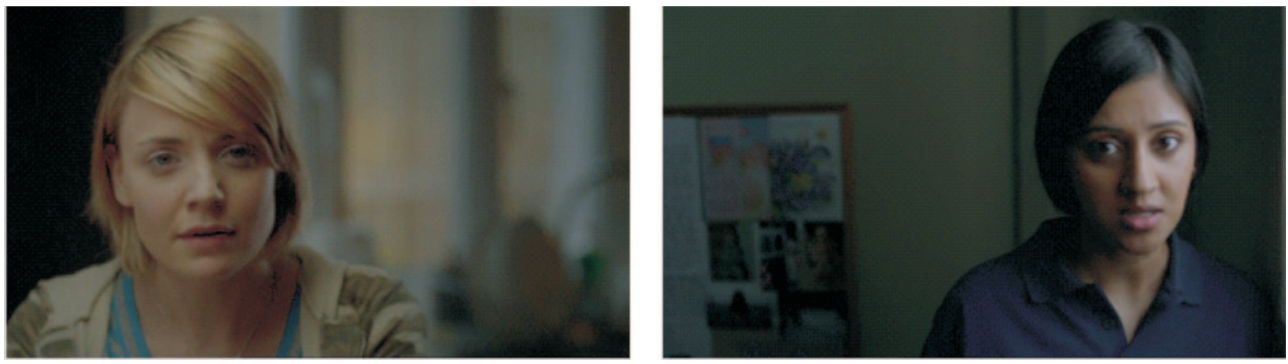